\title{
EXPERIMENTACIÓN ESCRITURAL Y AMBIGÜEDAD GENÉRICA COMO ESTRATEGIAS DE MUTACIÓN TEXTUAL EN MI PAÍS INVENTADO DE ISABEL ALLENDE
}

\author{
WRITING EXPERIMENTATION AND GENERIC AMBIGUITY \\ AS TEXTUAL MUTATION STRATEGYS IN MI PAÍS INVENTADO \\ FROM ISABEL ALLENDE
}

\author{
Federico Pastene Labrín \\ Universidad del Bío-Bío. Chillán, Chile \\ fpastene@ubiobio.cl
}

\begin{abstract}
Resumen: Este artículo analiza la obra Mi país inventado de Isabel Allende (2003) como un caso de mutación textual del 'ensayo identitario chileno', evidenciado en el desarrollo de un procedimiento de experimentación o de aprendizaje escritural, ya que la autora intenta textualizar un ensayo, pero en este proceso desemboca en una escritura genéricamente ambigua o de traslape con otras formas estereotípicas como la autobiografía y la confesión, revitalizando el discurso identitario en el contexto del Bicentenario nacional.
\end{abstract}

Palabras clave: Mutación textual, ensayo, identidad chilena.

\begin{abstract}
This paper analizes Mi país inventado from Isabel Allende (2003) as a case of textual mutation from chilean identity essay, demonstrated in the progress of an experimental procedure or writing learning, since the author intends to work on an essay text type, but in this process flows into a generically ambiguous writing overlapped with other stereotyped forms as autobiography and confession, revitalizing the identitarian discourse in the context of national bicentennial.
\end{abstract}

Keywords: Textual mutation, essay, Chilean identity.

Recibido: 12.03.2015 Aceptado: 06.04.2015. 


\title{
1. Introducción
}

T os Cambios que vive el discurso literario producido en América Latina Uresultan transgresores, rupturistas, abriéndose un abanico de nuevas posibilidades estéticas en una profunda tensión entre tradición y modernidad. Para Jorge Volpi (2009) la ficción en nuestro continente vive un momento inédito:

\begin{abstract}
Por primera vez no se es víctima de un deber ser novelístico. Se desvanecieron las normas, los cánones, las prohibiciones -escribe así o te fusilamos, no escribas asá o te ignoramos- y, salvo un puñado de críticos ponzoñosos y resentidos -es decir, un puñado de críticos-, nadie pretende fijar un baremo para medir a los escritores del continente. Por primera vez, insisto, uno puede elegir cualquier deriva y ser recibido con la misma legitimidad (o la misma indiferencia): los sutiles decoradores de miniaturas; los búfalos de la intriga policíaca; los que narran con pericia lo que sea; los vanguardistas de última hora; los etéreos de la metaficción; los mutantes de la novela y el ensayo ${ }^{1} ;$ (...) fuera de dos o tres apocalípticos que se rasgan las vestiduras, claman ante la decadencia, acusan al mercado de todos nuestros males -antes eran el comunismo y el imperialismo- y onanistas rabiosos, escriben reseñas con el único fin de triturar a sus vecinos, nadie lamenta el cambio (Volpi, 2009: 77).
\end{abstract}

El ensayo representa un discurso singular y polémico para la teoría y la crítica, puesto que en más de una oportunidad hace evidentes y problematiza varias cuestiones que otros géneros permiten considerar transparentes, o cuando menos posibles de postergar a la hora del análisis. Tal es, entonces, la reflexión que compartimos con Weinberg (2006) en el sentido de volver sobre estos 'casos especiales' o 'atípicos' de la literatura -diríamos del discurso y de la cultura en general- que presentan dificultades, por ejemplo, a la hora de clasificarlos, por lo tanto, es necesario aproximarnos al sistema, estudiar nuevas posibilidades y plantear propuestas capaces de clarificar este tipo de texto tan huidizo.

Desde un punto de vista canónico, es Michel de Montaigne (1533-1592) quien, con sus Essais (1580), inaugura un nuevo género donde variados te-

\footnotetext{
${ }^{1}$ La cursiva es nuestra.
} 
mas “(...) los someterá a juicio, los pesará y sopesará a partir de su propio y libre criterio, para reescribir desde sí mismo el conocimiento y ofrecer una nueva mirada sobre el mundo" (Weinberg, 2006: 210). El gesto primordial de Montaigne refleja los elementos claves iniciales del ensayo que, con el tiempo, otros escritores, filósofos e intelectuales, irán enriqueciéndolo: "Es el juicio un instrumento necesario en el examen de toda clase de asuntos; por eso yo lo ejercito en toda ocasión en estos Ensayos. Si se trata de una materia que no entiendo, con mayor razón empleo en ella mi discernimiento, sondeando el vado de muy lejos; luego, si lo encuentro demasiado profundo para mi estatura, me detengo en la orilla (...)" (Montaigne, 2003: 303). Su carácter reflexivo lo lleva a tratar los tópicos sin caer en una rígida exhaustividad, pero tratando de dar respuesta a algo nuevo con un especial interés indagativo, rodeado, eso sí, de la duda: "Desparramando aquí una frase, allá otra, como partes separadas del conjunto, desviadas, sin designio ni plan ${ }^{2}$, no estoy obligado a ser perfecto ni a concentrarme en una sola materia; varío cuando bien me place, entregándome a la duda y a la incertidumbre, y a mi manera habitual, que es la ignorancia" (Montaigne, 2003: 304). El ensayo, en consecuencia, nace como un intento abierto y libre de plantear las propias opiniones, lejos de la verdad irrefutable.

Pero, al mismo tiempo, es un género que adolece de estructura rígida, constituyendo no una debilidad, sino que otorga una oportuna libertad creativa al escritor. No está forzado a seguir un plan o método rígido preconcebido, más bien es libre de proseguir, interrumpir o aplazar el tema iniciado, sin que el ensayo carezca de concierto, porque su orden es interno, es el del yo-subjetivo del autor (Gómez, 1999). Es decir, contiene una evidente plasticidad genérica, ya que el ensayo es un tipo de texto que no tiene una superestructura fija, dado que es el particular modo de organizar su macroestructura la que va a determinar formas variadas de organización ensayística (Vila y Pilia, 2008).

Uno de los grandes pensadores latinoamericanos que otorgó nuevas dimensiones al ensayo, aprovechando su fuerza generadora, es Alfonso Reyes (1889-1959), cuyo interés radicaba, según Weinberg (2006), en conformar el ensayo en el vehículo y el lugar simbólico de expansión de la inteligencia

${ }^{2}$ La cursiva es nuestra. 
americana. Vislumbra la posición ética y estética del ensayo postpositivista, sella su presencia y lo proyecta con la inclusión de la concepción utópica. Es en su texto "Las nuevas artes" (1944) donde se manifiesta parte de este desafío, al ilustrar el ensayo como "este centauro de los géneros": "La literatura se va concentrando en el sustento verbal: la poesía más pura o desasida de narración, y la comunicación de especies intelectuales. Es decir, la lírica, la literatura científica y el ensayo: este centauro de los géneros, donde hay de todo y cabe todo ${ }^{3}$, propio hijo caprichoso de una cultura que no puede ya responder al orbe circular y cerrado de los antiguos, sino a la curva abierta, al proceso en marcha (...)" (Reyes, 1955: 403). Es este carácter abierto, flexible y dinámico que llevará a Reyes a emplear el ensayo como un instrumento para repensar las ideas en ámbitos directamente interrelacionados como el periodismo, la crítica y la literatura.

Si se considera uno de los rasgos relevantes ya mencionado acerca del ensayo -y, por supuesto, afín con nuestra hipótesis- como es su sinuosidad y flexibilidad formal, es, sin duda, Jorge Luis Borges (1899-1986) el adalid revolucionario que, con un lúcido ímpetu creativo, estético y de experimentación, extiende más allá las ricas potencialidades del ensayo contemporáneo, otorgándole a este género una libertad inusitada. Para José Miguel Oviedo (2003: 49) es 'impropio hablar de 'géneros' en Borges, porque continuamente escribió en los intersticios de ellos, creando ambigüedades y reverberaciones textuales que parodian los límites establecidos por la retórica entre esas categorías del discurso literario. Su obra puede verse como un conjunto de círculos concéntricos que se comprimen o expanden a voluntad, y en el que todo remite al centro que lo genera". Su énfasis está en la inventio, entendida como la capacidad de crear ideas nuevas aun a partir de las más conocidas. Así, el lenguaje expositivo y analítico del ensayo incorpora los elementos de la ficción y los recursos de la metáfora poética ${ }^{4}$.

${ }^{3}$ La cursiva es nuestra.

4 Para ejemplificar esta genial practica literaria borgeana: "No pocos ensayos de Borges pueden ser leídos como relatos o alegorías cuya función 'narrativa' es la de iluminar cuestiones estéticas o metafísicas. Un notable ejemplo de eso es 'El acercamiento a Almoostan', que apareció primero como una de 'Dos notas' en el libro de ensayos Historia de la eternidad (1936) y luego emigró a Ficciones (1944); es decir, el autor propuso dos lecturas distintas del mismo texto, facilitadas por su indefinición genérica" (Oviedo, 2003: 49). 
Resalta Oviedo (2003) en Borges un rasgo significativo del arte ensayístico como es que el examen de cualquier tema es continuo y circular, lo que justifica la presencia de notas y postdatas que revisan lo ya examinado en un proceso que va desde el planteamiento de una teoría o cuestión, pasando por el resumen de varias y discrepantes interpretaciones hasta el análisis de las alternativas que el asunto permita, incluyendo la suya, pero con la incertidumbre de que se tenga que repensar otra vez. Esta movilidad de Borges permite dejar "al lector en libertad para pensar o imaginar lo que quiera, y confirma además la ironía y el escepticismo filosófico de Borges respecto de las leyes que rigen el conocimiento humano y la búsqueda de la verdad" (Oviedo, 2003: 50).

Una vez revisadas someramente estas posibilidades que ofrece el ensayo desde su instauración como género hasta su realización en dos grandes escritores latinoamericanos, resaltando su poder generador de experiencias y sentidos, podemos afirmar que este soporte que sustenta la identidad chilena, que es el ensayo, ha tenido dificultades para incluir tan discutido contenido. El problema surge cuando el lector actual es capaz de identificar o discriminar el tema principal de una obra, pero entra en conflicto cuando, por ejemplo, no es capaz de distinguir el género discursivo que respalda el tema identitario: fenómeno al que hemos llamado incertidumbre genérica; o cuando comparamos un ensayo tradicional identitario con uno de reciente publicación y vemos que las estrategias escriturales innovan o transgreden regularidades que hasta ese momento habían sido empleadas sin distorsión. Los cambios, las transformaciones, las nuevas experimentaciones y confusiones no solo llegan al lector más o menos informado, sino también impregnan al mismo escritor, quien mediante el empleo de determinados procedimientos escriturales confronta su concepción de identidad con la herencia, con la tradición, con el canon.

La hipótesis que planteamos es que la obra Mi país inventado de Isabel Allende constituye un caso de mutación textual del 'ensayo identitario chileno', en la medida en que se desarrolla un procedimiento de experimentación o de aprendizaje escritural, donde la autora intenta textualizar un ensayo, sin embargo en este proceso desemboca en una escritura genéricamente ambigua o de traslape con otras formas estereotípicas como la autobiografía y la confesión, revitalizando el discurso identitario en el contexto del Bicentenario nacional. 


\section{Sobre el ensayo identitario}

Estos dos términos claves en el discurso literario -como ensayo e identidad- han estado interrelacionados desde su intensificación en los procesos emancipatorios americanos y en la construcción de un discurso muy fructífero que unificó y, al mismo tiempo, distinguió las nacionalidades que fueron surgiendo en América Latina. Dos conceptos que hoy deben escrutarse en un período postransitorio latinoamericano desde el 'ensayismo de tierra firme' al 'ensayismo de las orillas' (Weinberg, 2004). En otras palabras, el ensayo de la identidad chilena en un período de profundos cambios e inestabilidades, de mutación, de hibridación y de honda reflexión en los bicentenarios americanos.

Desde el inicio de este siglo ha habido un interés creciente por el tema de la identidad chilena, tópico en verdad recurrente en nuestra tradición cultural e intelectual, pero que, a nuestro parecer, se intensificó por la proximidad del Bicentenario de la República de Chile, momento, pues, oportuno para examinar la construcción y reconstrucción de nuestra concepción de identidad nacional.

No obstante, los estudios actuales sobre el ensayo identitario chileno son escasos. Cabe destacar a tres críticos que se han dedicado a estudiar en profundidad este tema: Roberto Hozven, Mario Lillo y Javier Pinedo (1988, 2000a, 200ob, 2002, 2006). Este último en varios artículos analiza las principales obras de los últimos cincuenta años en el contexto de construir una 'historia de las ideas de Chile', realizando una clara periodización del mismo. Por otra parte, Hozven (2001) y Lillo (2003) se han aventurado por un análisis más literario-retórico al estudiar cómo en el ensayo chileno se construye la idiosincrasia a través de alegorías identitarias.

En este último tiempo, la configuración del discurso identitario chileno -nos referimos al conjunto de escritores que mediante el discurso han propuesto o recogido una concepción de identidad nacional- ha proseguido su camino con bastante asiduidad motivado, entre otros, por el polo de atracción que ha significado el Bicentenario de la República ${ }^{5}$. Sin embargo,

${ }^{5}$ Nos referimos, por ejemplo, a El cuerpo de Chile de Marco Antonio de la Parra (2002); Chile, ¿de qué estamos hablando? Retrato de una transformación asombrosa de Patricia Politzer (2006), El sueño chileno. Comunidad, familia y nación en 
el ensayo identitario chileno actual evidencia significativas transformaciones mediante rasgos singulares que denotan una evolución de este tipo de discurso en su dimensión textual, cognitiva y sociocultural ${ }^{6}$.

\section{Concepto de mutación textual 7}

Para realizar nuestro estudio hemos tenido que generar una conceptualización propia que permita orientar el posterior análisis. De partida, concebimos 'mutación textual' como un proceso que consiste en la producción de cambios a nivel de la organización esquemática que opera en la estructura de las obras del conjunto textual ensayístico actual que trata la identidad chilena, produciéndose una modificación de su superestructura mediante el empleo de mecanismos discursivos o estrategias escriturales diversas (en el caso que tratamos, están la experimentación escritural y la ambigüedad genérica) que hacen que estos procedimientos, en ocasiones, destaquen por sobre la organización semántica de los discursos.

\section{Autora y obra en estudio}

Isabel Allende ${ }^{8}$ ha sido una escritora prolífica de obras literarias, especialmente, el género que ha cultivado con gran maestría es el subgénero na-

el Bicentenario de Eugenio Tironi (2005), Los nuevos chilenos y la batalla por sus preferencias de Pablo Halpern (2002), entre otros.

${ }^{6}$ Un caso de mutación textual que ya analizamos dentro de este corpus del discurso identitario chileno y que evidencia profundas transformaciones es La Olla deleitosa. Cocinas mestizas de Chile de Sonia Montecino, donde se despliegan las estrategias discursivas de simbolización disciplinaria, multigenericidad y multimodalidad (cf. Pastene, 2014).

${ }^{7}$ El concepto de mutación textual lo hemos generado a partir de aportaciones similares que se han estado haciendo en otros ámbitos. Cabe destacar a Carrasco (2003) con su concepción de mutación disciplinaria, Alvarado (2002) con mutación discursiva y Barreto (2007) con mutación semiótica.

${ }^{8}$ En 2010 recibe el Premio Nacional de Literatura, no exento de polémica como ha sido la mayor parte de su trayectoria literaria que ha sido reconocida más internacionalmente. Sin embargo, creemos que con este galardón la escritora se inscribe definitivamente en el canon literario chileno: "la excelencia y el aporte de su obra a la literatura, la que no solo ha concitado recepción tanto en Chile como en el extranjero, 
rrativo de la novela. Reconocidas son La casa de los espíritus, Hija de la fortuna, Retrato en sepia y otras históricas como Inés del alma mía donde ficción y realidad se entremezclan. No es menos cierto que también ha incursionado en otros géneros de carácter referencial (Fierro, 2005; Morales, 2001) como los discursos de la memoria, por ejemplo, en Paula.

De manera anecdótica, quisiera señalar que en una de mis clases una profesora, refiriéndose al texto en estudio, me señaló que la había leído, pero que no le quedaba claro a qué tipo de género discursivo correspondía o, más claramente, su lectura le había producido una incertidumbre genérica: ¿Era ensayo, autobiografía, memoria o testimonio? Aunque el paratexto ${ }^{9}$ editorial es un antecedente clave que nos permitió, finalmente, abrir sus páginas para escrutarla con mayor detenimiento y así intentar probar nuestra hipótesis: "En Mi país inventado, Isabel Allende vuelca todos sus sentimientos para recrear dos historias enlazadas, la de su país y la propia, con un tono intimista, de confesión autobiográfica poética".

Este nuevo libro de Allende fue publicado por la Editorial Sudamericana el 2003 en Buenos Aires y llegó a nuestras manos, sintiendo, curiosamente, la misma inquietud de la intrigada lectora. En este sentido, el estudio de $M i$ país inventado tiene que ir por los siguientes caminos que perfectamente se imbricarán. Comprobar si efectivamente es lo que enuncia el paratexto editorial, o estamos en presencia de un texto que experimenta ser ensayo, o que intenta definirse como una autobiografía o confesión. Más orientador es si preguntamos: ¿de qué manera ocurre la construcción esquemática de esta obra? ¿De qué forma se evidencian cambios en la manera de textualizar la identidad chilena? ¿Cómo se despliega esta mutación textual por experimentación y ambigüedad genérica?

sino que ha sido reconocida con múltiples distinciones y ha revalorizado el papel del lector (Boersner, 2010, en línea). Por nuestra parte, siempre hemos destacado el estratégico contrato de lectura que construye con sus lectores y, sobre todo, el empleo de distintos códigos que fortalecen el cultivo de su literatura (cf. Pastene, 2004).

${ }^{9}$ Para Genette (1987), paratexto es un término que se utiliza para designar aquello por lo que un texto se hace libro y se propone como tal a sus lectores, y más generalmente al público, es decir, la presentación editorial, el nombre del autor, los títulos, dedicatorias, epígrafes, prefacios, notas, etc. Se trata, pues, de cuantos elementos verbales y gráficos (dibujos, ilustraciones, etc.) acompañan al texto, formando parte del discurso literario que constituye la obra. 
El libro está constituido por 17 capítulos o temas donde es clave una introducción: "Unas palabras para comenzar", en cuyo contenido la autora traza su ruta de escritura que luego analizaremos. Así, a partir de los subtítulos, y de modo oscilante, conviven el discurso identitario nacional y su vida personal: "País de esencias longitudinales" con "Dulce de leche, organillos y gitanas"; "El paisaje de la infancia" con "Gente soberbia y seria"; "Sobre vicios y virtudes" (de los chilenos, por supuesto) y "Confusos años de juventud", finalizando con dos epifonemas esclarecedores: "Chile en el corazón” y "Ese pueblo dentro de mi cabeza".

\section{Experimentación escritural y ambigüedad genérica}

$\mathrm{Al}$ revisar la extensa productividad literaria de Isabel Allende, nos encontramos, de paso, con el antecedente de que un género literario no abordado por ella con profundidad o algo lejano ha sido el ensayo, esquema que, como postulamos, trata de construir con cierta dificultad en Mi país inventado. Por lo tanto, la autora emprende su escritura con un gran desafío no solo temático, sino más bien superestructural. Es decir, comienza un proceso de experimentación o de aprendizaje escritural que la conducirá a bordear otros géneros ya tratados con experticia o competencia genérica como los relatos, pero ahora el objetivo actual es distinto, por cuanto al reflexionar sobre la identidad chilena el género más usado por la tradición ha sido el ensayo. Esto la llevará, en consecuencia, a practicar una escritura genéricamente ambigua o de traslape entre los géneros sin perder de vista la configuración de un discurso identitario.

De este modo, entendemos aquí la ambigüedad genérica como el proceso escritural por el cual la autora transita abarcando más de un género específico, entremezclándose el ensayo, la confesión y la autobiografía, aunque tratando de no perder de vista el punto de partida que le da sentido y coherencia a su escritura, la función pragmática del discurso, que es 'reflexionar' sobre Chile a partir de su vida personal y familiar, visión que oscila entre la herencia, crisis y proyección identitaria ${ }^{10}$.

${ }^{10}$ Este punto no lo podemos desarrollar porque escapa al propósito principal del artículo. Sin embargo, en nuestra tesis doctoral, también hemos descubierto una vi- 
El título del libro ya nos evoca que lo central es el tema del país -Mi país(Chile), y no su persona en particular como gran centro irradiador, pero que además se agrega un carácter, una condición: 'inventado', que posee implicancias estéticas claves en relación con el proyecto de escritura emprendido. ¿Qué significado tiene, por lo tanto, este rótulo? El índice nos revela a simple vista este juego de espejos, esta ambigüedad que nos conduce a hipotetizar y al mismo tiempo indagar si es un ensayo o autobiografía o confesión, junto con la intención de querer decir algo sobre la identidad chilena.

En "Unas palabras para comenzar", primer subtítulo del escrito, Allende nos introduce a su singular modo de escritura. Situándose desde ya en el discurso como un sujeto activo de la enunciación: "(Yo) nací en medio de la humareda y mortandad de la Segunda Guerra Mundial (...)” (10), seguida de un pista esclarecedora en que se autodelata como principiante o novata en el oficio del ensayo: "Tengo poco entrenamiento para la reflexión ${ }^{11}$ (...) (10)", pero inmediatamente esta confesión rompe con esta expectativa porque agrega: “(...) pero en las últimas semanas me he sorprendido 'pensando ${ }^{12}$ en mi pasado con una frecuencia que sólo puede explicarse como signo de senilidad prematura" (10).

Ahora bien, si hubiésemos sido nosotros los sujetos de la enunciación, podríamos haber señalado con respecto a la remembranza: "me he sorprendido 'recordando' mi pasado", como parte de una respuesta típica de sentido común, claro está, sin pretensiones estéticas. El hecho de reiterar las construcciones verbales 'reflexionar' y 'pensar' nos adelantan notoriamente a los actos de habla típicos de una forma ensayística más que de recordar, donde predomina el acto de habla de 'contar', 'narrar', sobre todo, si se trata de una visión pretérita. Montaigne (2003) afirma: "Es el juicio un instrumento necesario para el examen de toda clase de asuntos, por eso yo

sión oscilante de identidad chilena que paradójicamente a veces expresan los ensayistas en cuanto a considerar la identidad en un momento como herencia, es decir, rasgos heredados de nuestro mestizaje inmutables y que definen nuestro modo de ser y actuar; crisis identitaria originada por el golpe cívico-militar de 1973 en Chile y proyección, con dos vertientes: una, que la identidad se reconstruye, cambia, y, segundo, la esperanza de subvertir la crisis identitaria con una vuelta a la utopía, al "sueño comunitario" (Cf. Pastene, 2010, 2011).

${ }^{11}$ La cursiva es nuestra.

${ }^{12}$ La cursiva es nuestra. 
lo ejercito en toda ocasión en estos ensayos.(...) Reflexiono sobre las cosas, no con amplitud sino con toda la profundidad de que soy capaz, y las más de las veces me gusta examinarlas por su aspecto más inusitado” (506). Sin embargo, esta conjetura tambalea porque insiste en el 'discurso de la memoria' (Fierro, 2005): "Dos sucesos recientes han desencadenado esta epidemia de recuerdos" (12) o "de que escribo como un ejercicio constante de añoranza" (12). Pero este descubrimiento, o revelación, también la hace actuar con sigilo, recelo, ante todo, -creemos- por el vacilante camino escritural genérico que ha emprendido: "De tanto despedirme se me secaron las raíces y debí generar otras que, a falta de un lugar geográfico donde afincarse, lo han hecho en la memoria; pero icuidado!, la memoria es un laberinto donde acechan minotauros" (13).

En cuanto a la construcción discursiva de la identidad, la autora sigue un juego que fluctúa entre la definición o búsqueda de su propia pertenencia identitaria, un poco trastocada por su condición de errante como ella afirma y los rasgos identitarios de Chile. Parte diciendo: "Si me hubieran preguntado hace poco de dónde soy, habría replicado, sin pensarlo mucho, que de ninguna parte, o latinoamericana, o tal vez chilena. Hoy sin embargo, digo que soy americana, ... que incluye a América de norte a sur (13).

Una vez más, en su preludio escritural, tropieza con este conflicto textual, genérico, por el cual afirmamos que esta es una escritura que vacila o, mejor aún, trata de experimentar con una forma de escritura poco abordada -el ensayo- que la hace caminar sobre un terreno movedizo, sin un plan claro y que se conecta con otras formas, siguiendo adelante, a pesar de que el trayecto sea sinuoso y que lo hace simultáneamente novedoso e interesante seguir el fluir de la pluma. Tan consciente está de este desafío que interpela al lector para que le ofrezca su ayuda: "Esas dos preguntas, la de mi nieto y la del desconocido en la conferencia, dieron origen a este libro, que no sé todavía hacia dónde va; por el momento divago, como siempre divagan los recuerdos ${ }^{13}$, pero le ruego que me acompañe un poco más" (14). Unas características que definen el ensayo son la duda y divagación, en el sentido de construir un discurso sin agotar el tema tratado. Ha dicho el maestro del ensayo, Montaigne (2003): "Varío cuanto me place y me

${ }^{13}$ La cursiva es nuestra. 
entrego a la duda y a la incertidumbre (...)" (505). Definiéndose, entonces, este oficio como un "pensar sin certezas" (cf. Navarro, 2007).

En consecuencia, la escritura de Allende ondea entre el presente y el pasado. Y confiesa que a través de los recuerdos de su vida y su familia, desea definir el carácter chileno, vale decir, mediante casos particulares realizar una generalización. Es una estratagema mediante la cual se apoya para configurar un discurso identitario marcado por su trayectoria vital y también imaginativa:

Dada la importancia que para nosotros tiene la familia, he escogido a la mía como hilo conductor para este libro, de modo que si me explayo en algunos de sus miembros es seguramente porque hay una razón, aunque a veces ésta sea sólo mi deseo de no perder esos lazos de sangre que me unen a mi tierra. Mis parientes servirán para ilustrar ${ }^{14}$ ciertos vicios y virtudes del carácter de los chilenos. Como método científico puede ser objetable, pero desde el punto de vista literario tiene algunas ventajas (42).

He aquí donde se produce esta transformación en construir la identidad, en usar como estrategia la memoria y vivencia personal y familiar para ensayar la identidad, lo que nos conduce a pensar si el relato autobiográfico también está presente y cómo se interrelaciona con el ensayo que, de todas formas y desde nuestro punto de vista, es el género dominante (top level structure) y donde los otros se interrelacionan subordinadamente.

Si postulamos que la autora se acerca al ensayo es porque toca directa e indirectamente algunos rasgos canónicos sobresalientes, o invariantes del género ensayístico, aunque con sus respectivas transgresiones y/o adecuaciones según el propósito de escritura que analizamos ahora. Intenta reflexionar sobre la caracterización identitaria chilena, desde un punto de vista absolutamente personal, subjetivo, cuyo estilo dialogado se aproxima cuando interpela al lector (cf. Gómez, 1999). La superestructura argumental se entremezcla con la narración, volviéndose en ocasiones difusa, no presentando un desarrollo lógico. Se argumenta, pero no al paroxismo. Es indudable que juega con la dimensión temporal (aquí y ahora), ya que el fluir escritural convive tanto con el pasado y con el presente y viceversa,

${ }^{14}$ Las cursivas son nuestras. 
recurso que evidencia esta experimentación, este intento por acercarse a un género no cultivado a partir de uno que domina con gran maestría, pero que en cierto modo le incomoda.

Por otra parte, desde el punto de vista de la ambigüedad genérica que se presenta en la obra, señalábamos que en el paratexto editorial se indica: "En Mi país inventado, Isabel Allende vuelca todos sus sentimientos para recrear dos historias enlazadas, la de su país y la propia, con un tono intimista, de confesión autobiográfica poética”. Si consideramos ahora la autobiografía, esta tiene como primer rasgo central canónico en que "se concentra en un yo que narra su existencia individual y en la cual se interpreta a sí misma" (Estébanez, 2001). Ahora bien, ¿qué ocurre en Mi país inventado? Esta característica en cierta forma se transgrede, porque a partir no solo de su existencia personal sino también familiar interpreta a su país, como se indicaba anteriormente en su objetivo de escritura. Además, un segundo rasgo de la autobiografía es "la recapitulación global de la vida implica una ordenación del pasado llevada a cabo por el yo reflexivo". Este elemento también se transgrede porque no existe una ordenación tal, por cuanto se van matizando e intercalando vivencias e impresiones tanto del presente como del pasado personal, familiar y nacional. Para Lejeune (1991), esa pasión del nombre propio va más allá de la simple vanidad de la autoría, puesto que a través de ella la persona misma reivindica la existencia, convirtiéndose el nombre propio en el tema profundo de toda autobiografía. En este contexto, como decíamos, se muta: no es su nombre propio, es el nombre de su país que lo describe identitariamente a cada instante. Asimismo, Estébanez (2001: 66) insiste en que la autobiografía es un relato retrospectivo en prosa -aunque en Allende el presente es siempre muy cercano- que una persona real hace de su propia existencia, poniendo el acento sobre su vida individual, en particular sobre la historia de su personalidad. Aquí, como indicábamos, la mutación se produce porque a partir de la vida individual y familiar pone el acento sobre la 'vida nacional', en particular, sobre la historia de un país: "Describiré un poco mi juventud, a ver si en el proceso ilumino algunos aspectos de la sociedad de mi país, que en ese tiempo era bastante más intolerante que ahora, lo cual es mucho decir" (91).

Asimismo, ha sido discutida la pertenencia de la autobiografía al ámbito literario. Un aspecto abordado por los críticos en relación con el estatuto 
literario de la autobiografía es el de la supuesta ausencia de carácter ficticio en la misma (rasgo que algunos teóricos consideran esencial en el texto literario), dado que el 'pacto autobiográfico', en principio, se da por sentado: que el narrador, persona real, actúa con sinceridad y que los destinatarios del mensaje pueden confiar en su veracidad. Sin embargo, dado el carácter de 'virtualidad creativa', más que referencial, que a juicio de Villanueva (citado por Estébanez, 2001: 67) habría que atribuir a estos relatos (en la autobiografía se trataría más que de una reproducción mimética, de una verdadera construcción de la identidad del yo), el elemento de ficción, o de autoengaño -sea éste consciente no-, sería un elemento importante en esta modalidad literaria. Con esta problemática teórica juega la escritora al enunciar: "No crea usted todo lo que digo, tiendo a exagerar y, tal como le advertí al principio, no puedo ser objetiva cuando de Chile se trata" (220).

Por último, cuando indagamos el género literario referencial de la confesión, también nos encontramos con algunas revelaciones no menos interesantes en cuanto a esta operación de mutación textual desarrollada en la obra. Para determinar en qué medida este género se instaura o se trasgrede, nos remitimos a las características centrales emanadas del estudio ya clásico de María Zambrano: La confesión: género literario (1995). La confesión difiere de la autobiografía en la intencionalidad pragmática de hacer públicos los secretos de la propia vida con un propósito de ejemplaridad, al ser analizados desde la óptica de la 'conversión', siguiendo canónicamente el caso de San Agustín de Hipona, desde la superación de la ignorancia, del error y el pecado hasta el reconocimiento de la verdad cristiana. Por supuesto que tal propósito religioso no se cumple en la obra estudiada y tampoco que el hacer pública su vida implique además una reacción ejemplarizadora. En cambio, lo que sí sucede es que no solo son sus 'secretos' los que hace públicos, sino también los 'secretos' del país al que (re)descubre. No necesariamente es un ordenado relato analéptico sobre la historia de su personalidad contada por ella misma (relato autodiegético). Tampoco se percibe una evolución o cambio intelectual y moral, al que se concede un valor ejemplar. Pero sí se cumple esta "creencia en el yo", desde donde se configura el discurso, aunque matizada no solo con su experiencia vital, sino también -como lo indicábamos- es a un país que también revela. 
La génesis escritural de las confesiones parte -según Zambrano- cuando la vida se ha hecho imposible. Se siente una insatisfacción, una ausencia, un déficit de realidad que al hombre se le hace insoportable aun estando aparentemente en ella. En cierta medida, en Mi país inventado lo que logra sobresalir, no con matices tan tajantes como expresa el rasgo genérico, es la necesidad de sentirse parte de un país que, aunque lejano espacial y temporalmente (dado que la autora vive en los Estados Unidos), puede ser reconstituido por la 'reflexión' de sus recuerdos e intentar superar mediante la escritura esta cierta insatisfacción que comenzó con un conflicto de identidad, con su propio conflicto que hizo perder ese sentido de identidad: "Por primera vez entonces fui parte de una comunidad, tenía patente de corso para hacer preguntas indiscretas y divulgar mis ideas, pero eso terminó bruscamente con el golpe militar de 1973, que desencadenó fuerzas incontrolables. De la noche a la mañana me convertí en extranjera en mi propia tierra (...)” (16).

En la confesión la historia urdida por la imaginación creadora que se aparta de la vida para mejor captarla, que huye de la realidad para, a través de la escritura, crear otra nueva, más real que la realidad, más vital que la vida misma, no es lo que sucede precisamente en Mi país inventado. La autora es partícipe directa de esa realidad a la cual alude sin escapar, sino, al contrario, la de tratar de abordarla lo mejor posible a través de la conjunción de la reflexión y la escritura.

En suma, Mi país inventado constituye un caso donde se operacionalizan unas estrategias discursivas de mutación textual en el discurso identitario chileno, al intentar textualizar mediante el ensayo (experimentación escritural) este discurso, incluyendo un despliegue escritural genéricamente de diálogo con otras formas como la autobiografía y la confesión, transgrediendo y subvirtiendo estos géneros, buscando ensayar el relato identitario. Cruza y descruza. Salta y salta de un vado al otro, experiencia estética que no tiene otro fin que tratar de (re)construir discursivamente la identidad chilena en el itinerario bicentenarista. La generación de su propia identidad personal ha ido aparejada con la del propio país que ha inventado y que vive en sus recuerdos: "El país que llevo en mí", "Ese pueblo dentro de mi cabeza”. 


\section{Referencias}

Allende, I. (2003). Mi país inventado. Barcelona: Sudamericana.

Alvarado, M. (2002). Mutación discursiva en las Ciencias Sociales chilenas. Lecturas de un texto de Francisco Gallardo. Revista Signos: Estudios de Lingüística, 51-52, 3-20.

Barreto, J. (2007). Mutación semiótica de un texto: Tensión entre el Popol Vuh y el Pop Wuj. Contribuciones desde Coatepec, 12, 39-50.

Boersner, J. (2010). Isabel Allende gana el Premio Nacional de Literatura de Chile 2010. Disponible en http://www.papelenblanco.com/novela/isabelallende-gana-el-premio-nacional-de-literatura-de-chile-2010.

Carrasco, I. (2003). La antropología poética como mutación disciplinaria. Estudios Filológicos, 38, 7-17.

De la Parra, M. (2002). El cuerpo de Chile. Santiago: Planeta.

Estébanez, D. (2001). Diccionario de términos literarios. Madrid: Alianza.

Fierro, J. (2005). El discurso de la memoria (1970-2005). Tesis doctoral inédita del Doctorado en Ciencias Humanas Mención Discurso y Cultura, Universidad Austral de Chile, Valdivia.

Genette, G. (1987). Seuil. Paris: Seuil.

Gómez, J. (1999). Teoría del ensayo. México: UNAM.

Halpern, P. (2002). Los nuevos chilenos y la batalla por sus preferencias. Santiago: Planeta.

Hozven, R. (2001). Alegorías identitarias en cuatro ensayos chilenos. Anales de Literatura Chilena, 2, 207-219.

Lejeune, Ph. (1991). L'autobiographie en France. Paris: A. Colin.

Lillo, M. (2003). Tropos y alegorías en el ensayo histórico chileno: La Fronda Aristocrática de Alberto Edwards. Taller de Letras, 32, 27-35.

Montaigne, M. (2003). Ensayos completos. Madrid: Cátedra.

Morales, L. (2001). La escritura de al lado. Géneros referenciales. Santiago: Cuarto Propio.

Navarro, J. (2007). Pensar sin certezas. Montaigne y el arte de conversar. Madrid: FCE.

Oviedo, J. (2003). Borges: El ensayo como argumento imaginario. Letras Libres, 56, 48-50. Disponible en http://www.letraslibres.com/revista/convivio/borges-el-ensayo-como-argumento-imaginario

Pastene, F. (2004). La era del acceso y de la novela popular: Una lectura de Hija de la fortuna de Isabel Allende. Theoria, 13, 111-120. . (2010). Mutación textual en el discurso ensayístico de la identidad chilena. Tesis doctoral inédita del Doctorado en Ciencias Humanas Mención Discurso y Cultura, Universidad Austral de Chile, Valdivia. . (2011). El ensayo: Una poética del pensamiento. En C. Reyes (coord.), 
Tesis doctorales destacadas 2009-2010 (pp. 34-43). Santiago: Red Universitaria Cruz del Sur.

. (2014). La Olla Deleitosa: Un caso de mutación textual en el ensayo identitario chileno. Literatura y Lingüística, 29, 16-33.

Pinedo, J. (1988). La ensayística y el problema de la identidad 1960-1988. En J. L. Gómez Martínez y J. Pinedo (coords.), Chile: 1968-1988 (pp. 231-264). University of Georgia, Series on Hispanic Thought, 22-25.

. (2000a). Ensayo chileno y política. En R. Cánovas y R. Hozven (eds.), Crisis, apocalipsis y utopías. Fines de siglo literatura latinoamericana (pp. 429-435). Santiago: Pontificia Universidad Católica de Chile.

. (200ob). Pensar en (la) transición. Intelectuales chilenos durante el proceso de transición a la democracia. 1990-1999. Universum, 15, 189-232. . (2002). Cinco momentos claves en el ensayo literario chileno contemporáneo. En A. Vilanova (coord.), Actas del X Congreso de la Asociación Internacional de Hispanistas 4 (pp. 893-906). Madrid.

. (2006). Los intelectuales y la creación de la identidad Nacional. Universum, 21, 245-247.

Politzer, P. (2006). Chile: ¿de qué estamos hablando? Retrato de una transformación asombrosa. Santiago: Sudamericana.

Reyes, A. (1955). Obras completas de Alfonso Reyes. México: FCE.

Tironi, E. (2005). El sueño chileno. Comunidad, familia y nación en el Bicentenario. Santiago: Taurus.

Vila, M. y Pilia, N. (eds.). (2008). Travesías del ensayo latinoamericano del siglo XX. Neuquén: Ediciones Universidad Nacional del Comahue.

Volpi, J. (2009). El insomnio de Bolívar. Cuatro consideraciones intempestivas sobre América Latina en el siglo XXI. Buenos Aires: Debate.

Weinberg, L. (2004). Ensayo e identidad. Dos términos en correlación. En P. Cabrera (coord.), Pensamiento, cultura y literatura en América Latina (pp. 45-56). México: CIICH-UNAM y Plaza y Valdés.

. (2006). Situación del ensayo. México: Centro Coordinador y Difusor de Estudios Latinoamericanos. UNAM.

Zambrano, M. (1995). La confesión: Género literario. Madrid: Siruela. 